\title{
APORTES TEÓRICO-PEDAGÓGICOS PARA UM ENSINO FUNCIONAL DE LÍNGUA PORTUGUESA
}

\author{
Fabrício da Silva Amorim*
}

RESUMO: Este trabalho operacionaliza aportes teóricos advindos dos estudos linguísticos como contributos para o ensino de Língua Portuguesa. O objetivo geral é descrever uma proposta pedagógica por meio da qual o estudo da língua, em sala de aula, seja "funcional". Assim, apresentam-se diretrizes para a concepção/construção de um roteiro de ensino de Português sob a perspectiva funcional da linguagem, considerando os diferentes eixos que compõem esse ensino na Educação Básica, a saber: "leitura e produção textual", "literatura" e "análise linguística".

PALAVRAS-CHAVE: Diretrizes pedagógicas; Ensino de português; Funcionalismo.

\section{Introdução}

Na Linguística moderna, desde que o paradigma formalista deixou de ser hegemônico, entre os anos 1970 e 1980, as discussões em torno da língua, em suas múltiplas dimensões (gramatical, textual, social etc.), diversificaram-se, gerando importantes reformulações e ampliações teórico-metodológicas no campo da pesquisa linguística. Essa diversificação do olhar científico sobre a língua suscitou também um repensar no campo pedagógico: no caso do ensino de Língua Portuguesa no Brasil, surgiram questionamentos sobre o seu caráter estritamente prescritivo, em que a gramática normativa se revelava como ponto de partida e de chegada para o ensino-aprendizagem.

Hoje, em virtude do desenvolvimento da Linguística em diferentes vertentes e da inserção de objetivos pedagógicos nessa área de estudo, há um número significativo e crescente de trabalhos voltados ao ensino de Língua Portuguesa (COAN; FREITAG, 2010; DUARTE, 2013; MARTINS; TAVARES, 2013; AMORIM, 2014; MARTINS et al, 2014; AVELAR, 2017). A grande maioria desses trabalhos assenta-se na Sociolinguística Educacional - também referida como Pedagogia da Variação Linguística (ZILLES; FARACO,

\footnotetext{
* Doutor em Estudos Linguísticos pela Universidade Estadual Paulista Júlio de Mesquita Filho (Unesp). Professor do Instituto Federal da Bahia (Ifba). Realizou, pelo PDSE/CAPES, estágio de pesquisa na Université Catholique de Louvain (Bélgica).
} 
2015) - e busca descrever um modelo de ensino pelo qual a língua é abordada como um conjunto de variedades materializado através de enunciações orais e escritas. Trata-se, portanto, de um paradigma pedagógico que objetiva a superação de práticas "gramatiqueiras" para a implantação de um ensino de língua descritivo e funcional.

O presente artigo alinha-se ao quadro geral de estudos que, pedagogicamente aplicados, visam à operacionalização de aportes teóricos advindos dos estudos linguísticos como contributos para o ensino de língua portuguesa. O objetivo geral é mostrar como se pode desenvolver uma prática pedagógica por meio da qual o estudo da língua, em sala de aula, seja funcional.

O qualificador "funcional", neste texto, deve ser entendido de duas maneiras. A primeira diz respeito a sua acepção mais comum, segundo a qual indica "função", "propósito", "utilidade". A segunda assume um caráter mais teórico, referindo-se ao paradigma da Linguística moderna conhecido como Funcionalismo, dentro do qual "função" designa o caráter instrumental da língua, no sentido de seus usos serem relativamente determinados por intenções sociointerativas dos seus usuários. Deseja-se, com isso, apresentar uma proposta de ensino baseada em práticas "sociocomunicativamente utilitárias".

Para um ensino funcional de Língua Portuguesa, deve-se priorizar, portanto, objetivos pedagógicos pragmáticos e assumir como objeto de ensino-aprendizagem a língua em uso, a qual se revela heterogênea quanto às suas materializações formais e discursivas prosa/poesia; fala/escrita; gêneros textuais etc.

Contudo, é preciso alertar que, neste trabalho, não se apresentam sequências didáticas, mas aportes que, sendo de natureza teórica e pedagógica, permitem alicerçar a concepção e a elaboração de tais sequências. Assim, apresentam-se, ao longo das seções a seguir, diretrizes (algumas não tão inéditas, haja vista estarem presentes em documentos oficiais) para uma concepção/construção de um roteiro de ensino de Português sob a perspectiva funcional aqui defendida, considerando os diferentes eixos que compõem esse ensino na Educação Básica, a saber: "leitura e produção textual", "literatura" e "análise linguística”. 


\section{Ensino funcional de Português: diretrizes e reflexões}

O objetivo desta seção é apresentar orientações, fundamentadas em perspectivas teórico-pedagógicas atuais ${ }^{1}$, para a construção de um roteiro de ensino capaz de explorar a língua portuguesa de maneira pragmática, tanto do ponto de visto utilitário (para, por exemplo, instrumentalizar a(o) estudante para os "usos públicos" da língua) quanto do ponto de vista linguístico (para explorar a língua em sua diversidade formal e discursiva). Para alcançar tal objetivo, apresentam-se as subseções a seguir como uma sequência de itens que remete ao planejamento de uma aula/ementa da disciplina Língua Portuguesa na Educação Básica.

Dessa forma, são descritos os objetivos do ensino de Língua Portuguesa, etapa primordial de qualquer planejamento, na medida em que determina muitos aspectos das demais fases de quaisquer ações pedagógicas (ANTUNES, 2014). Em seguida, analisa-se a natureza dos conteúdos capazes de contemplar um modelo funcional de ensino, considerando os eixos da leitura e produção textual, da literatura e da análise linguística. Na sequência, aborda-se o papel do material didático, que pode ser selecionado ou elaborado para auxiliar as práticas funcionais de ensino. Por fim, discute-se a questão da avaliação de habilidades e competências linguísticas, dentro do modelo ensino proposto, e apresentamse as considerações finais.

\section{Os objetivos}

$\mathrm{Na}$ Linguística moderna, a teoria funcionalista da linguagem, assim como se observou em outros paradigmas teóricos, sofreu aprimoramentos que a reconstituíram em diferentes vertentes, como, por exemplo, a Gramática Discursivo-Funcional (HENGEVELD; MACKENZIE, 2008) e a Gramática de Construções (TRAUGOTT; TROUSDALE,

\footnotetext{
${ }^{1}$ Do ponto de vista teórico, as perspectivas adotadas referem-se ao Funcionalismo, assumido em sua vertente clássica, e à Sociolinguística Educacional. Em termos pedagógicos, cotejam-se recomendações dos PCN (1998) e da nova BNCC (2017). Todas essas perspectivas, embora possam remeter a textos de décadas pretéritas, são tomadas como atuais por se oporem ao ensino tradicional - e obsoleto - que restringe o estudo da língua portuguesa à prescrição da norma-padrão.
} 
2013). Todos os funcionalismos, apesar de reconhecidas divergências teórico-metodológicas que os particularizam, são praticados a partir de uma mesma premissa epistemológica, segundo a qual a língua é um sistema sensível aos usos que dele são feitos, tornando-se instável, ou seja, variável e mutável. Embora se distancie, sobretudo em termos metodológicos, dos funcionalismos, a Sociolinguística também se desenvolve a partir da ideia de língua como um sistema heterogêneo, o que, dentro desse quadro teórico, se explica por razões sociais: fatores constitutivos da realidade social de uma comunidade linguística, como gênero e classe social, são responsáveis por fazer da língua uma estrutura variável e mutável.

No que tange à aplicação pedagógica dos pressupostos advindos dessas teorias, pode-se afirmar que não há distinções claras entre o(s) Funcionalismo(s) e a Sociolinguística, visto que ambas as vertentes apregoam um ensino de língua baseado na descrição das variedades linguísticas, em seus aspectos formais e discursivos, para a ampliação do reportório (sócio)linguístico das(os) estudantes.

Desse modo, a concepção de ensino de Língua Portuguesa aqui defendida emerge dessas duas vertentes, firmando o seguinte objetivo geral para essa disciplina: tornar as/os estudantes linguisticamente autônomas(os) e aptas(os) a se comunicarem, por meio da fala e da escrita, de maneira adequada e eficiente. É possível observar que tal objetivo subjaz a várias diretrizes dos documentos oficiais destinados a pautar o ensino de Português nos diferentes níveis da Educação Básica:

[...] espera-se que o aluno amplie o domínio ativo do discurso nas diversas situações comunicativas, sobretudo nas instâncias públicas de uso da linguagem, de modo a possibilitar sua inserção efetiva no mundo da escrita, ampliando suas possibilidades de participação social no exercício da cidadania (BRASIL, 1998, p. 32).

No Ensino Médio, o foco da área de Linguagens e suas Tecnologias está na ampliação da autonomia, do protagonismo e da autoria nas práticas de diferentes linguagens; na identificação e na crítica aos diferentes usos das linguagens, explicitando seu poder no estabelecimento de relações; na apreciação e na participação em diversas manifestações artísticas e culturais e no uso criativo das diversas mídias. (BRASIL, 2017, p. 471) 
Não é possível cumprir esse objetivo principal de maneira direta e abrupta: é necessário atrelá-lo a um conjunto de metas de natureza social, discursiva e (meta)linguística. As metas sociais caracterizam-se como ações que, fundadas na função sociointerativa da língua, objetivam o resgate ou fortalecimento da autoestima linguística das(os) estudantes, para torná-las(os) autônomas(os), sobretudo, no exercício dos usos públicos da língua, sentindo-se seguras(os), por exemplo, para reclamarem, por telefone ou pessoalmente, de um serviço mal prestado, ou para apresentarem-se a uma vaga de emprego através de um email.

As metas discursivas abrangem habilidades para a compreensão e produção do(s) discurso(s). O reconhecimento de teias discursivas, nos textos falados e escritos, e a construção de discursos subjetivos e políticos são exemplos de habilidades caracterizadas como discursivas. Por fim, as metas (meta)linguísticas envolvem dois tipos de operações, a saber, as operações de reflexão sobre a língua (metalinguísticas) e as de leitura e produção textual (linguísticas). Assim, reconhecer um determinado elemento como uma conjunção ou um verbo é uma habilidade metalinguística, enquanto inferir, interpretar e estabelecer coerência entre dois enunciados representam habilidades linguísticas.

As metas descritas devem diluir-se e mesclar-se, nas diferentes atividades propostas, em uma aula de Português. Entretanto, dependendo do eixo que se deseja focar (cf. subseção a seguir), uma ou outra meta será naturalmente priorizada. O cumprimento desse conjunto de metas pode garantir o desenvolvimento de competências comunicativas, assim descritas por Silva (2017 - destaques da autora):

(a) competência linguística: domínio das formas e das funções dos elementos fonético/fonológico, morfológico, sintático, lexical e semântico da língua para se obter sucesso comunicativo em qualquer situação em que fizer uso dela;

(b) competência textual: domínio das características relativamente estáveis dos gêneros textuais para se fazer uso adequado - e/ou subversivo - da língua nesses gêneros;

(c) competência discursiva: domínio da situação de interação. Capacidade do usuário da língua de contextualizar sua interação para que seu produto textual seja adequado ao contexto de enunciação. (SILVA, 2017, p. 80) 
Os aspectos apresentados nesta seção revelam-se basilares para a execução de um ensino funcional de Português, na medida em que

A questão dos objetivos e da natureza da abordagem é fundamental, pois a ela estão atreladas muitas outras. Ou, melhor dizendo, tudo está muito conectado no trabalho pedagógico: as atividades são decorrentes dos objetivos que escolhemos, esses são decorrentes das concepções temos acerca de como são as línguas, que relações têm com outros objetos da criação humana, que funções desempenham, enfim. Concepções, objetivos, tipos de abordagem, práticas pedagógicas, atividades: tudo é uma cadeia, que, por sua vez, se assenta na contingência das estruturas institucionais disponibilizadas e vai até os macroprocessos socioculturais. Qualquer quebra nos elos dessa corrente repercute no sucesso do todo (ANTUNES, 2014, p. 60).

Nas seções a seguir, portanto, encontram-se os demais elos da corrente teóricopedagógica aqui cotejada como uma forma de contribuir para um ensino de Língua Portuguesa pelo qual se explorem os "usos linguísticos" de maneira social, discursiva e gramatical, a fim de conduzir as/os estudantes a reconhecerem a sua funcionalidade, apropriandose deles para o seu desenvolvimento (sócio)linguístico.

\section{Os conteúdos}

Os conteúdos da disciplina Língua Portuguesa, em qualquer nível de ensino, devem ser pensados a partir de três eixos: "leitura e produção textual" - "literatura" - "análise linguística”. Cada eixo deve envolver um conjunto de atividades teóricas e práticas centradas no texto. Assim, independentemente do eixo, o ponto de partida e de chegada dessas atividades deve ser o texto, compreendido como uma materialização discursiva - oral ou escrita - que, "sociointeracionalmente" circunscrito, releva-se sob a forma de um determinado gênero textual. Por conseguinte, o eixo da leitura e produção textual torna-se central, no ensino de Português, em virtude do seu caráter abrangente (e urgente!):

Ora, se as línguas somente se realizam com uma função sociointerativa, e isso se efetiva exclusivamente sob a forma de textos, não há como fugir à demanda de eleger o texto e seus componentes como $\mathrm{O}$ ob- 
jeto de estudo. A gramática - não esqueçamos - é um desses componentes. Apenas UM. Nem mesmo o componente principal. (ANTUNES, 2014, p. 43 - destaques da autora)

Os conteúdos previstos para o eixo da leitura e produção textual, conforme indicam os PCN e a BNCC, devem cobrir habilidades linguísticas necessárias à compreensão e à análise de textos, bem como às operacionalizações - como adequação da linguagem, revisão, retextualização, etc. - para a produção textual. A análise de gêneros textuais, em seus aspectos estilístico-gramaticais e discursivos, e a produção pautada pela diversidade desses gêneros devem representar, assim, os conteúdos mais essenciais da disciplina Língua Portuguesa.

Vale lembrar também que emergem do trabalho focado no eixo da leitura e produção textuais aspectos relevantes para a formação cidadã, permitindo traçar e alcançar "metas sociais" e "metas discursivas", como assinalado na seção anterior. Assim, como os gêneros textuais têm uma função sociodiscursiva (uma notícia, uma carta aberta e uma crônica, por exemplo, são instrumentos de interação social) e serve a diferentes propósitos, por meio deles, devem-se promover, em sala de aula, reflexões e práticas não apenas para a formação linguística, mas também cidadã.

Os conteúdos do eixo literário, conforme se pode inferir, centram-se nos gêneros textuais literários - crônica, conto, cordel etc. - uma vez que

É importante lembrar que os textos literários são, obviamente, textos. Então, eles são, no mínimo, úteis para o desenvolvimento da competência comunicativa dos estudantes, da mesma forma que os textos jornalísticos, publicitários, científicos e didáticos são úteis para esse desenvolvimento. Os textos literários são lugares propícios para a descoberta de novas palavras e de novos usos de palavras já conhecidas. Mas isso é o mínimo. (OLIVEIRA, 2010, p. 190)

Dessa forma, além da dimensão linguística, o texto literário, socialmente engajado ou não, permite o acesso às dimensões histórica, sociocultural e subjetiva. Quanto à dimensão sociocultural, por exemplo, cabe destacar que o trabalho com os gêneros literários revela-se bastante profícuo para uma prática textual de "humanização", já que, a partir deles, é possível tratar dos mais diversos temas sociais: ao suscitarem emoções através de enredos 
e metaforizações, tais gêneros sensibilizam as(os) estudantes quanto a questões que, muitas vezes, são ignoradas quando veiculadas na esfera dos gêneros científicos ou jornalísticos.

A função poética da linguagem, amplamente presente nos mais diversos gêneros literários, representa uma ferramenta de acesso às dimensões linguística e subjetiva. Entre outras alternativas, para explorar essa função, é preciso que a leitura e a interpretação expressiva de textos literários sejam praticadas, em sala de aula, por professoras e estudantes. Esse tipo de atividade caracteriza-se como uma "prática de oralidade", tão necessária quanto a escrita para o desenvolvimento de habilidades linguísticas, além de contribuir para que as(os) estudantes experimentem a literatura como recurso de fruição.

A seleção de conteúdos para o eixo da literatura requer, ainda, atenção para a distinção, conforme estabelece Oliveira (2010), entre "estudar literatura" e "usar literatura": a primeira diz respeito à prática de ensino centrada na história da literatura (abordagem das escolas literárias); a segunda se refere a atividades funcionais pautadas pela literatura, isto é, práticas de leitura e de escrita de gêneros literários:

Uma forma prática de o professor incentivar o uso da literatura em sua sala é a criação de oficinas de leitura ou de círculos de leitura. Ele escolhe contos, crônicas, poemas e cordéis, por exemplo, para fazer uma leitura com todos os alunos com o objetivo de dar-lhes uma oportunidade de lerem textos literários e se expressarem a seu respeito, sem nenhuma intenção avaliativa. (OLIVEIRA, 2010, p. 173)

O eixo da análise linguística, por sua vez, contempla os conteúdos gramaticais. Trata-se, talvez, do eixo que mais exija cautela na sua abordagem, na medida em que ainda persiste no País um forte discurso em defesa da tradição gramatical como uma prática eficiente para o desenvolvimento de habilidades linguísticas.

De acordo com os documentos oficiais que normatizam o ensino de Português no Brasil, deve-se priorizar a "análise linguística”, e não a "análise gramatical” (entendida em sentido estrito). Assim, analisar linguisticamente a língua significa investigá-la em sua diversidade de usos, explicáveis por motivações socioculturais e históricas. Os conteúdos do eixo 
da análise linguística não se restringem, portanto, àqueles listados nas gramáticas normativas, uma vez que, nessa abordagem, outras normas linguísticas, além da norma-padrão, devem ser incluídas nas atividades didáticas.

Dessa maneira, dois pontos revelam-se cruciais: i) a escolha dos conteúdos tradicionalmente previstos para a descrição da norma-padrão e ii) o desenvolvimento de um trabalho que considere outras variedades linguísticas, como o português brasileiro culto ${ }^{2}$ e popular. Em relação ao primeiro ponto, devem-se priorizar conteúdos que, efetivamente, podem ser operacionalizados para a produção textual (acentuação gráfica, usos das conjunções, emprego da crase, concordância verbo-nominal, para citar alguns). Assuntos estritamente classificatórios, embora possam representar um "conteúdo clássico" (de importância histórica para área de conhecimento em questão), devem ser necessária e "funcionalmente" operacionalizados, visto que, como explica Avelar (2017):

[...] da forma como os professores a utilizam, condicionados em grande parte pelos manuais de gramática, a nomenclatura acaba sendo um fim em si mesma, em vez de ser empregada como um meio ou instrumento para ajudar os alunos em reflexões produtivas sobre a língua. As aulas de gramática acabaram por se transformar em um grande esforço para levar os alunos ao mero (mas não simples) exercício da classificação, com o único intuito de nomear corretamente as diferentes classes de palavras, as várias funções sintáticas dos termos da oração, aos tipos de oração coordenadas e subordinadas, entre outros aspectos. Pouco ou nenhum esforço é dispendido para que, a partir do uso de uma nomenclatura, o aluno explore essa ferramenta metalinguística como um recurso destinado a práticas criativas de produção e recepção textual. (AVELAR, 2017, p 48 - grifo acrescido)

O segundo ponto requer das professoras um empenho maior para a elaboração das atividades, sobretudo quando não se dispõe de uma formação (sócio)linguística adequada. A dificuldade incide no fato de que ainda é escasso material didático com propostas de

\footnotetext{
2 Define-se como norma culta o espectro de variedades do português utilizado por falantes com níveis elevados de letramento, em situações mais monitoradas, constituindo, assim, a norma de prestígio em uso do português. Por sua vez, a norma-padrão diz respeito à variedade prescrita pelas gramáticas normativas mais tradicionais e em uso apenas nos gêneros textuais escritos altamente monitorados. Representa, assim, uma "norma linguística abstrata" (Cf. AMORIM, 2014).
} 
análise de outras variedades linguísticas, impondo a essas profissionais a tarefa de concebêlas e de elaborá-las, o que, devido às conhecidas condições sob as quais trabalha a grande maioria das professoras e professores brasileiros, nem sempre é possível. ${ }^{3}$

\section{Os materiais didáticos}

Materiais didáticos, em sentido lato, dizem respeito a instrumentos multimodais que intermedeiam o processo de ensino-aprendizagem: livros (para)didáticos, apostilas, módulos, computadores, recursos audiovisuais etc. Talvez este seja o ponto mais complexo para um texto que se destina às professoras de Português do Brasil: em um país onde os investimentos em Educação são escassos e esparsos, não se pode esperar que essas profissionais disponham de materiais didáticos. Entretanto, acreditando-se, ainda que de maneira demasiadamente otimista, que a democratização da internet alcançou a grande maioria delas, pode-se apresentar sugestões para uma melhor operacionalização/elaboração de materiais didáticos para a aula de Português.

Conforme assinalado, independentemente do eixo com que se deseja trabalhar, o texto deve constituir o elemento norteador da aula de Língua Portuguesa. Considerando a modalidade escrita, é, portanto, imprescindível que se viabilize a exposição das(os) estudantes a diferentes gêneros textuais. As escolas que dispõem de livros didáticos, distribuídos para estudantes ou disponíveis na biblioteca escolar, configuram um cenário menos desafiador.

Com o Programa Nacional do Livro Didático (PNDL), os livros que chegam às escolas públicas apresentam, em geral, uma abordagem adequada para o trabalho com os gêneros. Alguns, por exemplo, articulam atividades dos três eixos - leitura e produção textual, literatura e análise linguística - em torno de um determinado gênero. O livro didático,

\footnotetext{
${ }^{3}$ Uma alternativa viável, para a elaboração de atividades destinadas à descrição do português (culto) brasileiro, seria a consulta a gramáticas do português brasileiro, como, por exemplo, Castilho e Elias (2012) e Bagno (2012).
} 
como defende Amorim (2018), representa uma ferramenta de inegável relevância para professoras e professores brasileiros, uma vez que

[...] ainda que não seja distribuído em todas as escolas do país, constitui o material didático a que a grande maioria de professoras e professores recorre para a elaboração de suas aulas. Dessa forma, embora se defenda a autonomia da/do professora/professor para questionar e elaborar seus materiais didáticos, pode-se afirmar que, na realidade brasileira, em que, por razões amplamente conhecidas, as/os profissionais da Educação dispõem de pouco tempo e condições para a formação contínua, o livro didático acaba assumindo um papel notável nas suas decisões pedagógicas. (AMORIM, 2018, p. 55)

Tendo ou não materiais didáticos à sua disposição, na escola, a consulta a uma coleção atual de livros didáticos, aprovada pelo PNLD, pode fornecer à professora subsídios para estudo (os Guias do Professor, além de orientar a execução de atividades baseadas no livro, costumam fornecer textos teóricos importantes para a formação/reflexão docente) e elaboração de material próprio.

Não dispondo do livro, tampouco da possibilidade de imprimir textos para turma, uma alternativa seria a exibição dos textos por meio de recurso audiovisual. Todavia, em uma situação mais extrema, a completa ausência de materiais impressos pode ser compensada pela leitura colaborativa - e expressiva! - dos gêneros textuais que se deseja trabalhar. Nesse caso, podem-se desenvolver atividades híbridas do ponto de vista da modalidade textual, estabelecendo ralações entre oralidade-escrita (sobre o texto lido/ouvido, as/os estudantes podem escrever comentários, responder a questões de interpretação, bem como elaborar seus próprios textos).

\section{As avaliações}

Em toda discussão pedagógica, é possível observar que são unânimes os apelos para que os métodos avaliativos sejam diversificados e processuais. Entretanto, o tema da avaliação ainda está longe de esgotar-se: o debate sobre métodos para aferição da aprendizagem continua dividindo opiniões - e teorias - no que diz respeito à sua eficácia e aos seus padrões (tradicional $v$ s. inovador). 
No caso do ensino de língua portuguesa, a diversidade e a gradualidade do processo avaliativo devem alinhar-se aos objetivos estabelecidos. Considerando a proposta funcional aqui desenvolvida, é preciso encontrar métodos capazes de permitir que a professora acompanhe os progressos e os entraves no desenvolvimento das competências e habilidades linguísticas das(os) estudantes ${ }^{4}$. Desse modo, a avaliação não pode ser vista como um mero teste de conhecimento, mas como um instrumento capaz de promover o exercício de habilidades linguísticas e cognitivas, a fim de tornar possível que a professora afira o desempenho de suas(seus) estudantes nesse exercício.

O texto, como já assinalado, deve representar o ponto de partida e de chegada no ensino de Português; portanto qualquer modalidade de avaliação nessa disciplina deve ser planejada e executada a partir dele. Ora, sendo orais ou escritos e se materializando em diversos gêneros, os textos, como objeto de/para avaliação, garantem diversidade e, vale salientar, dinamicidade no processo de avaliação. Uma avaliação de Português pode, assim, constituir-se como oral ou escrita, priorizando a construção de gêneros textuais; pode, ainda, a depender do gênero e do exercício que se deseja propor, mesclar os eixos da leitura e produção textual, da análise linguística e da literatura, ou mesmo focar apenas um deles.

Nesse sentido, é preciso discutir, especialmente, dois pontos: a ausência de avaliações orais e a preponderante presença de avaliações escritas no ensino de Língua Portuguesa no Brasil. O primeiro ponto é resultado da ausência da própria oralidade como objeto de conhecimento nesse ensino; a prática de gêneros textuais orais, em sala de aula, quando acontece, resume-se, na imensa maioria dos casos, à apresentação de seminários, debates e dramatizações. Tais atividades são pertinentes, mas, geralmente, carecem de critérios obje-

\footnotetext{
${ }^{4}$ Segundo a BNCC, competência é "a mobilização de conhecimentos (conceitos e procedimentos), habilidades (práticas, cognitivas e socioemocionais), atitudes e valores para resolver demandas complexas da vida cotidiana, do pleno exercício da cidadania e do mundo do trabalho" (BRASIL, 2017, p. 8). A execução prática de uma competência, o "saber fazer", diz respeito à babilidade.
} 
tivos e sistemáticos para que possam representar, efetivamente, tanto um exercício de oralidade em sala quanto uma modalidade de avaliação de habilidades e competências linguísticas.

Cabe assinalar que, em uma aula de Português, a oralidade não é ensinada, mas praticada, sobretudo sob a forma de gêneros que requerem monitoramento e adequação à norma culta ${ }^{5}$. É o caso, por exemplo, dos gêneros que se tornaram clichê quando, em geral, as professoras pretendem executar atividades orais, como o seminário e o debate. Para que esses gêneros sejam adequadamente operacionalizados para atender ao objetivo norteador do ensino funcional de Português, a saber, promover autonomia, adequação e eficiência na comunicação oral e escrita, deve-se considerar que "tratar a oralidade como objeto de ensino implica identificar, refletir e utilizar os recursos linguísticos e a variedade de usos da língua na modalidade oral em função de práticas sociais específicas" (SOUSA e DORNELLES, 2017, p. 59).

Dessa maneira, a proposição de qualquer atividade oral deve contar com um roteiro que sistematize as suas etapas e conduza as(os) estudantes a terem consciência do monitoramento linguístico. A apresentação de um seminário, por exemplo, pode representar um interessante exercício oral se, desde a sua preparação, a professora orientar as(os) discentes sobre postura, voz e adequação linguística, focando aspectos de concordância verbal e nominal. Com isso, é possível dispor, ainda, de um conjunto de critérios para que o seminário se torne efetivamente uma avaliação oral. É possível também que se realizem avaliações que explorem o oral e o escrito, como a produção e leitura de gêneros textuais literários (poesia, conto, fábula etc.).

Em relação ao segundo ponto, é inegável que as avaliações escritas têm caráter hegemônico no ensino de modo geral. Isso se deve, essencialmente, ao valor simbólico da "prova", adquirido, por sua vez, pela valoração quantitativa: em uma escala de zero a dez,

${ }^{5}$ Falas espontâneas e demais usos informais da oralidade não devem ser desprezados ou sofrer sanções na aula de Português: embora as(os) estudantes dominem os registros orais mais informais, praticá-los em sala, quando pertinente, pode contribuir para o processo de desinibição linguística, essencial para que possam desenvolver a prática de usos mais monitorados. 
definem-se boas/bons e más/maus alunas(os). Além disso, reforça esse cenário a existência de provas escritas como principal etapa de seleção em vestibulares e concursos. Contudo, não se deseja aqui demonizar essa modalidade de avaliação, mas ressignificá-la sob a ótica de um ensino funcional.

Primordialmente, as avaliações escritas da disciplina Língua Portuguesa devem configurar-se como um exercício de escrita em sala de aula. Nesse sentido, a produção escrita de um determinado gênero textual ou a elaboração de uma resposta que exija articulação de conceitos são tarefas adequadas para esse tipo de avaliação: escrever para responder a uma prova também é uma prática social. Nessa modalidade, torna-se fundamental que haja um alto grau de monitoramento por parte da professora, que deve elaborar enunciados claros, em linguagem escorreita, e propostas de produção textual devidamente contextualizadas e alinhadas a atividades prévias de leitura.

Nas avaliações escritas com foco em análise linguística, vale retomar a distinção entre esse tipo de análise e a gramatical. Em termos pedagógicos, a análise gramatical atrelase à prática tradicional de ensino da gramática normativa, em que interessa a identificação dos usos linguísticos considerados corretos e de categorias gramaticais (classificação). Nessa perspectiva, a prova de Português constitui-se, essencialmente, de um conjunto de questões sobre os usos adequados ou não à norma-padrão e de caráter classificatório. Não há, nesse caso, preocupação com aspectos discursivos ou a exploração da classificação gramatical como meio para a compreensão/construção de um texto: trata-se, assim, de uma mera prova sobre gramática, e não de um exercício de reflexão gramatical. É bem-vinda, na presente discussão, a observação de Avelar (2017):

Não podemos deixar aqui de mencionar um dos principais terrores dos alunos no trabalho com a sintaxe: a famigerada classificação das orações em períodos compostos, por meio da qual eles costumam ser avaliados quanto à habilidade de nomear os mais diferentes tipos de oração coordenada e subordinada. Não tenho, particularmente, nada contra atividades desse tipo, uma vez que, se bem trabalhadas, podem colaborar para o desenvolvimento de competências necessárias ao exercício da taxonomização (elaborar abstrações, estabelecer critérios de distributividade, fazer generalizações, organizar informações, testar hipóteses, entre outras), importante em diversos 
campos de saber e áreas de investigação científica. O problema [...] é quando a nomenclatura gramatical serve apenas para avaliar o aluno quanto à memorização dos rótulos para as partes do discurso e para os termos sintáticos da oração, sem qualquer propósito para além disso (AVELAR, 2017, p. 115).

A análise linguística, por sua vez, ultrapassa os limites da classificação gramatical, remetendo "à análise das unidades da língua (fonema, morfema, sintagma, palavra) em função do contexto, do texto, do discurso e do tema. Ou seja, analisa-se a língua, não em suas unidades isoladas, mas na sua relação com unidades mais amplas (texto, gênero e discurso) (BEZERRA; REINALDO, 2013, p. 51 - grifo acrescido). Assim, a prova escrita de Português, quando focada em gramática, deve abordar os elementos linguísticos em suas funções - e não necessariamente em sua classificação -, as quais só podem ser reconhecidas quando tais elementos são considerados a partir do todo de que são parte, ou seja, do texto. ${ }^{6}$ Afinal,

O professor precisa estar consciente de que conhecer a nomenclatura gramatical não é o objetivo das aulas de português. De que adianta os alunos decorarem termos como pronome pessoal do caso reto e pronome pessoal do caso oblíquo, se eles não souberem identificar as referências que os pronomes estabelecem? Dominar a metalinguagem não implica o domínio da leitura e da escrita (OLIVEIRA, 2010, p. 250).

\section{Considerações finais}

As expansões e aprimoramentos teóricos por que passaram diferentes vertentes da Linguística moderna reverberam também no campo pedagógico, já que grande parte das mudanças observadas no ensino de Língua Portuguesa no País se deve a contributos fornecidos pelos estudos linguísticos. Tanto o polo formalista quanto o funcionalista, em que se desenvolvem pesquisas sobre a linguagem, têm desempenhado papel relevante na formação e requalificação de professoras e professores de Português, bem como na formulação de diretrizes presentes em documentos pedagógicos oficiais.

${ }^{6}$ Nos últimos anos, a prova de Linguagens e suas Tecnologias do Enem tem privilegiado questões que exploram aspectos semântico-discursivos da língua, aproximando-se do que aqui se descreve como análise linguística. 
O polo funcionalista, no qual se reúnem vertentes assentadas na premissa de que a língua é um sistema suscetível a sofrer variação e mudança, devido, sobretudo, aos usos que os falantes fazem dele, tem contribuído para um ensino de português menos prescritivo e mais textual-discursivo. Desse modo, conforme cotejado ao longo deste trabalho, para um ensino funcional, a língua portuguesa deve ser pedagogicamente abordada, sob diferentes eixos, como um instrumento que serve a diversas funções, sendo necessário explorá-las, na sala de aula, a partir de suas materializações em gêneros textuais orais e escritos.

Espera-se, assim, que o presente texto, ao discorrer sobre aportes basilares para a concepção e elaboração de um roteiro destinado ao ensino funcional de Português, possa auxiliar professoras e professores na tão desafiadora - e imprescindível! - tarefa de promover, neste país, formação (sócio)linguística e cidadã.

\title{
THEORETICAL-PEDAGOGICAL REMARKS FOR A FUNCTIONAL TEACHING OF PORTUGUESE
}

\begin{abstract}
This work operationalizes theoretical remarks regarding the Linguistics as contributions for the teaching of Portuguese. The main objective is to describe a pedagogical proposal by which the language study, in the classroom, becomes functional. Therefore, it presents some instructions for a conception/production of a teaching guide based on the functional perspective on language, taking into account the three segments that holds the teaching of Portuguese in Basic Education: reading comprehension and writing; literature and linguistic analysis.
\end{abstract}

KEYWORDS: Functionalism; Pedagogical instructions; Portuguese teaching.

\section{REFERÊNCIAS}

AMORIM, F. S. Variação diacrônica e ensino. Revista Tabuleiro de Letras, v. 12, n. 3, p. 5165, 2018. Disponível em:<https://www.revistas.uneb.br/index.php/tabuleirodeletras/article/view/5566>. Acesso em: 02 jun. 2019.

. Ensino do português brasileiro: por uma pedagogia descolonial. Web-Revista Sociodialeto, v.05, p. 111-138, 2014. Disponível em: < https://www.researchgate.net/publication/292695294_ENSINO_DO_PORTUGUES_BRASILEIRO_POR_UMA_PEDAGOGIA_DESCOLONIAL>. Acesso em: 02 jun. 2019. 
ANTUNES, Irandé. Gramática contextualizada: limpando “o pó das ideias simples”. São Paulo: Parábola, 2014.

AVELAR, J. Saberes Gramaticais: formas, normas e sentidos. São Paulo: Parábola Editorial, 2017.

BAGNO, M. Gramática pedagógica do português brasileiro. São Paulo: Parábola Editorial, 2012.

BEZERRA, M. A.; REINALDO, M. A. Análise Linguística: afinal, a que se refere?. São Paulo: Cortez, 2013.

BRASIL. Ministério da Educação. Secretaria da Educação Básica. Base nacional comum curricular - Ensino Médio. Brasília, DF, 2017.

BRASIL. Parâmetros Curriculares Nacionais - Língua Portuguesa / Ministério da Educação Fundamental. - 3. Ed. - Brasília: MEC, 1998.

CASTILHO, A. T.; ELIAS, V. Pequena gramática do português brasileiro. São Paulo: Editora Contexto, 2012.

COAN, M.; FREITAG, R. M. K. Sociolinguística variacionista: pressupostos teórico-metodológicos e propostas de ensino. Domínios de Lingu@Gem, v. 4, p. 173-194, 2010. Disponível em: <http://www.seer.ufu.br/index.php/dominiosdelinguagem/article/view/11618>. Acesso em: 19 nov. 2019

DUARTE, M. E. L. Sobre o ensino de gramática nos níveis fundamental e médio: por que como e quando? Matraga (Rio de Janeiro), v. 19, p. 41-60, 2013. Disponível em: < https://www.e-publicacoes.uerj.br/index.php/matraga/article/view/22620>. Acesso em: 19 nov. 2019.

HENGEVELD, K; MACKENZIE, J.L. Functional Discourse Grammar: A typologicallybased Theory of Language Structure. Oxford: Oxford University Press, 2008.

MARTINS, A. M.; VIEIRA, S. R.; TAVARES, M. A (Org.). Ensino de português e sociolinguística. São Paulo: Contexto, 2014.

MARTINS, M. A.; TAVARES, M. A. (Org.). Contribuicões da sociolinguística e da linguistica histórica para o ensino de lingua portuguesa. Natal: EDUFRN, 2013.

OLIVEIRA, Luciano A. Coisas que todo professor de português precisa saber: a teoria na prática. 1. ed. São Paulo: Parábola Editorial, 2010. //

SILVA, L. A. Por um ensino produtivo de gramática. In: Vânia Cristina Casseb-Galvão; Maria Helena de Moura Neves. (Org.). O todo da lingua: teoria e prática do ensino de português. São Paulo: Parábola Editorial, 2017, p. 77-95.

SOUSA, R. D.; DORNELLES, C. "Eu quero aprender a falar": o estudo dos gêneros orais na aula de língua portuguesa. Raído, Dourados, MS, v. 11, n. 25, jan./jun. 2017. Disponível em: <http://ojs.ufgd.edu.br/index.php/Raido/article/view/5042>. Acesso em: 19 out. 2019. 
TRAUGOTT, E.; TROUSDALE, G. Constructionalization and Constructional Changes. Oxford: Oxford University Press, 2013.

ZILLES, A. M. S.; FARACO, C. A. (Org.). Pedagogia da variação linguística: língua, diversidade e ensino. São Paulo: Parábola Editorial, 2015.

Recebido em: 28/03/2020.

Aprovado em: 19/05/2020. 